\title{
Attempted Predation of a Child by a Gray Wolf, Canis lupus, near Icy Bay, Alaska
}

\author{
MARK E. MCNAY ${ }^{1}$ and Philip W. MoONEY ${ }^{2}$ \\ ${ }^{1}$ Alaska Department of Fish and Game, 1300 College Road, Fairbanks, Alaska 99701-1599, USA \\ ${ }^{2}$ Alaska Department of Fish and Game, 304 Lake Street, Sitka, Alaska 99835-7563, USA
}

McNay, Mark E. and Philip W. Mooney. 2005. Attempted predation of a child by a Gray Wolf, Canis lupus, near Icy Bay, Alaska. Canadian Field-Naturalist 119(2): 197-201.

On 26 April 2000 a six-year-old boy was attacked and repeatedly bitten by a Gray Wolf (Canis lupus) in a logging camp near Icy Bay, Alaska. The animal's behavior during the attack clearly contained elements of predation. The wolf was killed shortly after the attack and found to be in normal physical condition; tests for rabies and canine distemper were negative. Low densities of ungulate prey and increased energetic demands associated with denning may have influenced the wolf's behavior, but we believe the wolf's habituation to people was a more significant factor contributing to the attack. Food-conditioning may have facilitated the habituation process, but there was no evidence the attack resulted from a food-conditioned approach response.

Key Words: Gray Wolf, Canis lupus, food conditioning, habituation, predation, wolf aggression, wolf attack, Alaska.

Documented aggression by wild Gray Wolves (Canis lupus) toward humans in North America is rare and often characterized by bluff charges or brief attacks involving a single bite (Munthe and Hutchison 1978; Jenness 1985; Scott et al. 1985; Mech 1998; Strickland 1999; McNay 2002a, 2002b [Case 15, page 12]). However, in April 2000 near Icy Bay, Alaska, a wolf pursued and attacked a six-year-old boy, then attempted to carry the boy to nearby cover. The wolf inflicted 19 laceration and puncture wounds on the boy's back, legs, and buttocks before being driven away and killed. Among recent published accounts of wolf aggression toward humans in North America, none describe such persistent, aggressive behavior by a healthy wolf.

The Alaska Department of Public Safety (ADPS) conducted an investigation immediately following the attack. Later, we conducted a separate review of the incident. Details of the attack were obtained from our interviews with five people who either witnessed the attack or observed the wolf's behavior prior to the attack, and from the ADPS (2000*) report that included interviews with six additional people. We describe this uncommon incidence of wolf aggression and discuss possible motivations for the attack.

\section{The Setting}

The attack occurred at a logging camp near Icy Bay, Alaska $\left(59^{\circ} 58^{\prime} \mathrm{N}, 141^{\circ} 39^{\prime} \mathrm{W}\right)$. The camp was in a 13 ha clearing surrounded by dense forest. It served 80 seasonal workers and seven permanent families. An unpaved road from a log sort yard on the shore of Icy Bay ran through the camp and continued westward. Gray Wolf habitat near Icy Bay is confined to about $100 \mathrm{~km}^{2}$ of Sitka Spruce/Western Hemlock (Picea sitchensis/Tsuga heterophylla) forest surrounded by steep mountains, ice fields, and the Gulf of Alaska. A nar- row corridor of forest along the beach leads to more suitable wolf habitat $50 \mathrm{~km}$ to the west (Figure 1).

The diet of Gray Wolves near Icy Bay probably contains a wide variety of foods. Moose (Alces alces) are migratory and no more than 20 are present at any time of the year. Mountain Goats (Oreamnos americanus) are found in steep terrain but are not often killed by wolves. Snowshoe Hares (Lepus americanus), Beaver (Castor canadensis), small rodents, and migratory birds are potential prey. Marine foods (fish, invertebrates, and marine mammals) are available as carrion on the beaches and Coho Salmon (Oncorhynchus kisutch) migrate into spawning creeks during late summer.

\section{The Attack}

About 9:00 a.m. on 26 April 2000, John Stenglein (age 6) and Keith Thompson (age 9) were playing in the forest edge on the camp's north perimeter. They heard a noise, looked up and saw a wolf standing $3 \mathrm{~m}$ away behind a low tree branch. The wolf showed its teeth and growled as it crouched under the branch toward them. The boys remained still until the wolf stepped forward and snarled again. John, wearing oversized boots, ran slowly and awkwardly. Keith ran ahead calling for help. Keith's dog, a male Labrador Retriever, was 50-100 m from the boys, but ran toward the wolf as the boys emerged from the forest (Figure 2).

John ran about $40 \mathrm{~m}$ across open gravel, then stumbled and fell. The dog briefly fought the wolf near the tree line, but the wolf disengaged and attacked John while the boy was on the ground. John struggled to escape, but the wolf lifted him off the ground, turned, and attempted to carry the boy toward the forest. Because of the boy's size ( $27 \mathrm{~kg}$ ) and loose clothing, the wolf had difficulty carrying the boy and it began dragging John toward the tree line. Four adults res- 

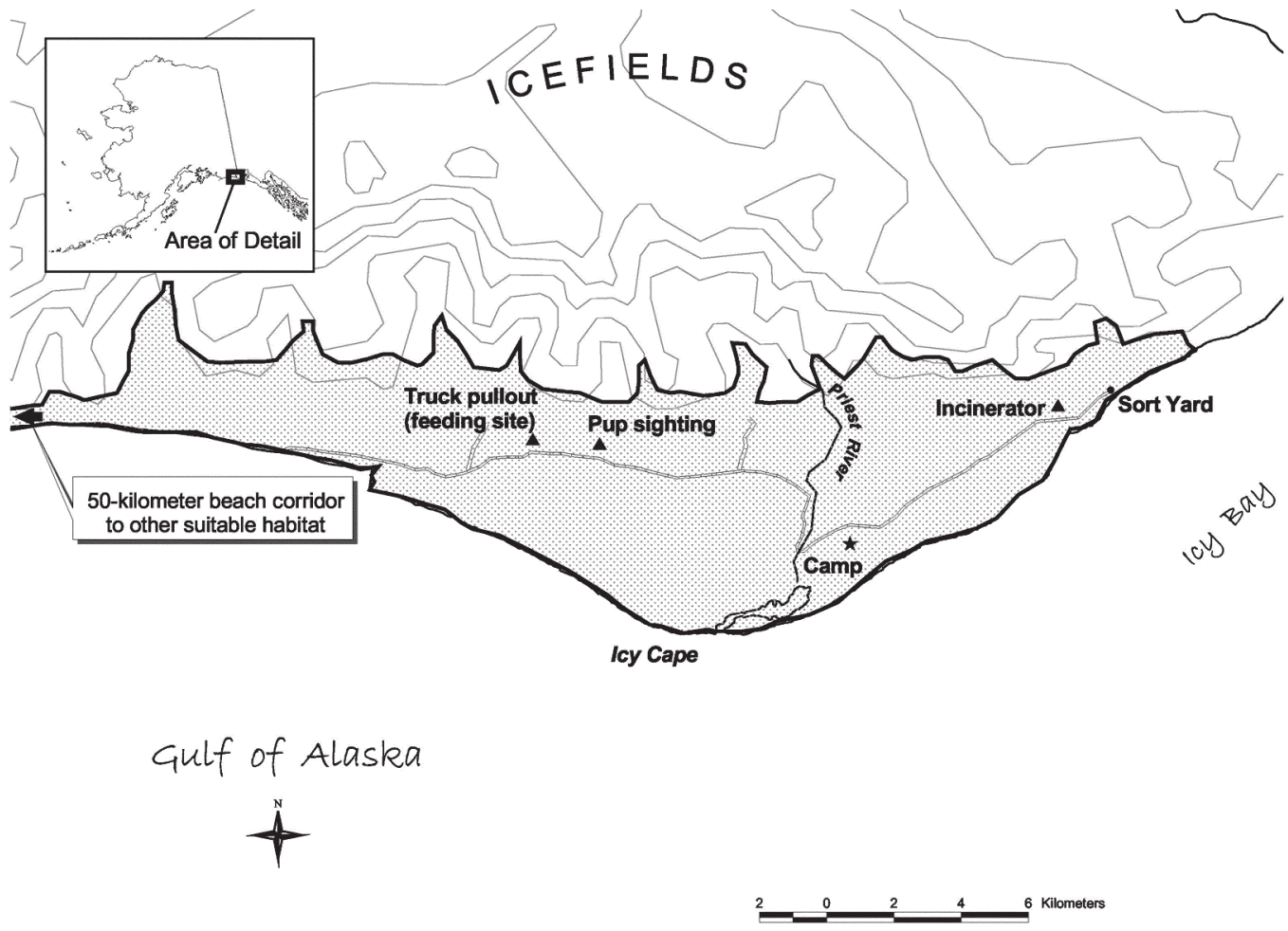

FIGURE 1. Detail showing location of the Icy Bay logging camp relative to available wolf habitat (shaded area) in the vicinity of Icy Cape.

ponded to the boys' cries for help and approached to within $1 \mathrm{~m}$ while shouting and throwing rocks. The dog bit at the wolf's hind legs, but the wolf focused on the boy and largely ignored the harassment by both the dog and rescuers. At one point the wolf released its grip on the boy after being struck by a rock, but then attacked again. Eventually, when the dog positioned itself between the child and the wolf, a rescuer grabbed the boy and carried him away (Alaska Department of Public Safety, 2000*; S. Norberg and T. Thompson, Icy Bay, Alaska, personal communication).

The dog and the three remaining rescuers drove the wolf into the forest, but the wolf was defiant and reluctant to leave. Less than 10 minutes later, Keith's father arrived with a rifle. He walked into the forest and briefly called with a predator call. Almost immediately, the wolf stepped onto a trail $80 \mathrm{~m}$ behind him. The man turned and fired once, killing the wolf (Alaska Department of Public Safety 2000*).

A post-mortem examination revealed no apparent physical disabilities that would have contributed to the wolf's behavior. The wolf's size (approximately $35 \mathrm{~kg}$ ) appeared small compared to other wolves in that area, but body fat levels were normal. The stomach contained remnants of natural foods, including cartilage and hair, possibly from a Beaver. The wolf tested negative for rabies and canine distemper. The wolf wore a tightly fitting radio collar that had caused hair loss on its neck, but no abrasion to the skin (Blake 2000*).

\section{The Wolf's History}

The wolf had been captured and fitted with a radio collar in March 1996 at 10 months of age (Alaska Department of Public Safety 2000*). It dispersed from its natal range (100 km west of Icy Bay) during winter 1997-1998. The radio was not heard again, but a radiocollared wolf, believed to be the same wolf, was seen twice by Alaska Department of Fish and Game (ADF\&G) biologists in June 1998, $50 \mathrm{~km}$ west of Icy Bay. During one of those sightings the collared wolf was with another, uncollared wolf.

Almost a year later, in April 1999, the collared wolf was seen on a logging road $18 \mathrm{~km}$ west of Icy Bay. The previous day, Mooney witnessed a truck driver throw food to an uncollared female wolf at the same site. Following that feeding incident, the logging company reemphasized their policy prohibiting the feeding of wildlife and there were no further known cases of wolves being fed. 


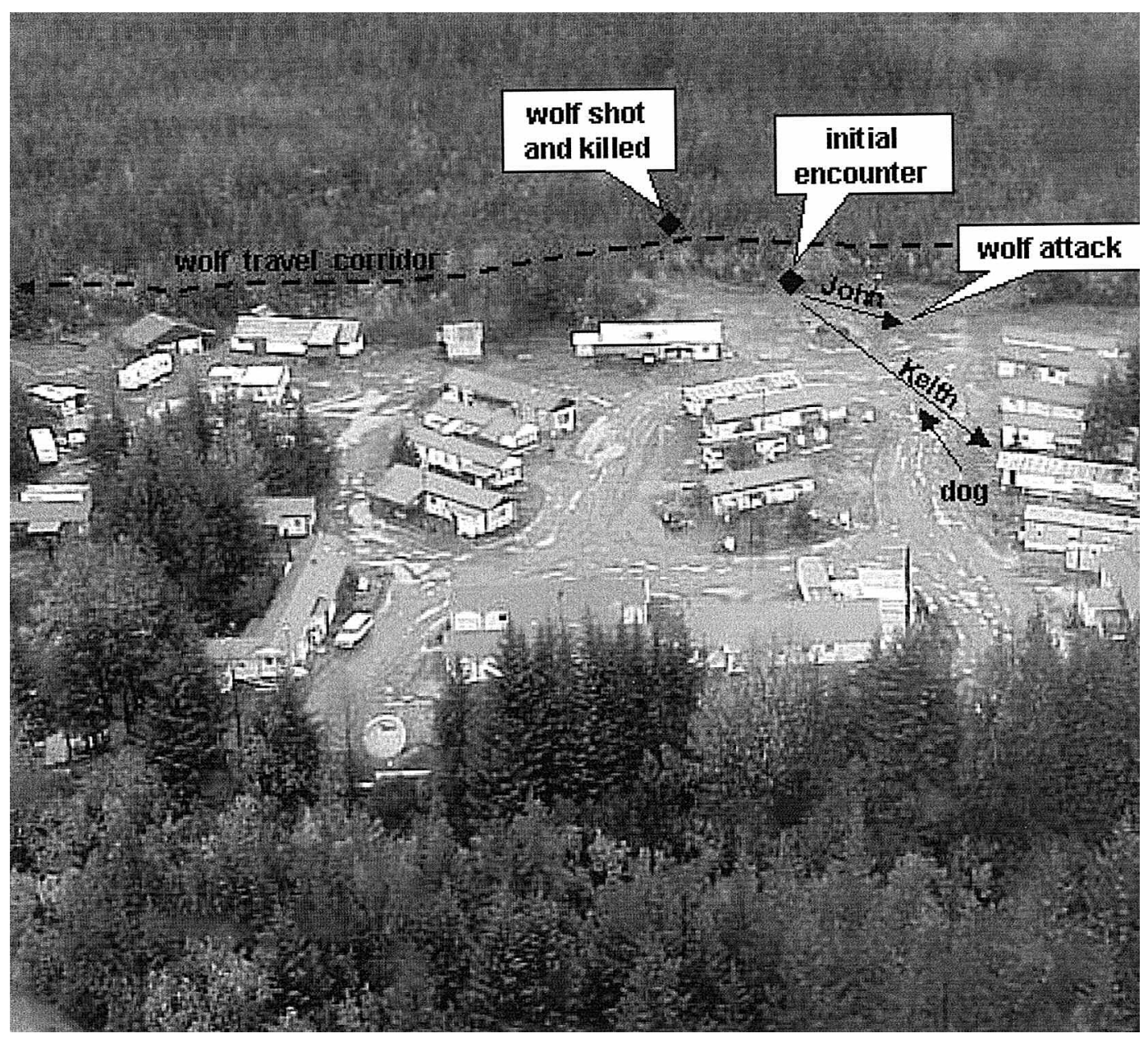

FIGURE 2. Aerial photo of the Icy Bay logging camp showing location of the wolf encounter and attack sites. Photo by P. Mooney.

Over the next year, the collared wolf exhibited increasingly bold behavior. It was seen at least seven times by camp residents along the north perimeter of camp, on the road, and near the log sort yard. Between September 1999 and April 2000, people encountered the wolf at close range at least four times, but it never approached or demonstrated aggressive behavior toward people. However, the wolf was suspected in an attack that seriously injured a dog in summer 1999.

The pattern of sightings suggests the wolf occupied a territory and was not a transient. At 5 years of age most wolves have passed through a dispersal period during which they disassociate from their natal pack and travel alone before finding a mate (Fuller et al. 2003). The collared wolf's dispersal began at the normal age of 2 years. The sightings of the collared wolf and a female wolf at the same location on consecutive days in April 1999 suggests a mated pair, and on 2 July
2000 a female wolf with five pups crossed the road $6 \mathrm{~km}$ from the camp in front of an approaching vehicle. One of the pups was photographed by the driver. That sighting confirmed a den or rendezvous site was nearby. Those pups would have been born in April or early May 2000, about the time of the attack.

The collared wolf was often seen near the sort yard so it routinely traveled the $15 \mathrm{~km}$ between the denning area and the sort yard. A dry streambed along the northern perimeter of the camp provided a natural travel route. Residents frequently saw the collared wolf near camp in early summer, but not in late summer of 1999. That change in activity coincided with increased food availability as salmon moved into streams $6 \mathrm{~km}$ from the camp.

The camp's garbage was collected and incinerated daily. The Alaska Department of Public Safety investigator inspected all garbage disposal facilities and 
specifically asked 11 camp residents if they knew of wolves being fed or obtaining food near the camp. The investigator concluded there was no evidence that the animal was drawn into the area by active or passive feeding within the year prior to the attack (Alaska Department of Public Safety 2000*).

\section{Discussion}

Until the day of the attack, the collared wolf had never approached or acted aggressively toward people, but it had demonstrated increasingly fearless behavior. The habituation process was probably facilitated by the camp's central location in the small, isolated area of wolf habitat. The wolf probably encountered people frequently, but people would have been unaware of the wolf's presence during most encounters, because the camp, road, and sort yard were all surrounded by dense forest. The presence of dogs may have encouraged the wolf to periodically patrol and scent mark along the camp's perimeter. Company policy made it difficult for camp residents to hunt or trap near the camp or near worksites, thereby creating a defacto wolf protection zone where wolves were not conditioned to avoid humans. That pattern of frequent, low intensity (i.e., passive and inconsequential) encounters, irregularly spaced over a long period, is the ideal recipe for habituation (Kimmel 1973).

It seems unlikely that agonistic behavior toward the dog precipitated the wolf's attack because the dog was indoors until just before the attack and was 50-100 m from the boys during the wolf's initial approach. The dog skirmished with the wolf at least three times, but suffered no injuries. During the attack, the wolf focused on the boy and ignored the dog, but both boys had been with the dog earlier that morning. It's possible the dog's scent on their clothing played a role in the wolf's initial approach.

Snarling behavior is generally associated with agonism in wolf social interactions and can precede either offensive or defensive aggression (Zimen 1982). Highranking wolves harass subordinates by crouching and threatening to spring, baring their teeth, or with an open mouth (Mech 1970). However, the snarling behavior witnessed by the boys prior to the Icy Bay attack does not rule out predation as a motivation. Among several predatory attacks upon children in India, wolves stalked toward children then snarled or showed their teeth before attacking (K. Rajpurohit, Wildlife Institute of India, personal communication).

Predation involves a sequence of connected behaviors that include: (a) orientation toward the prey; (b) following (i.e., stalking or rushing approach); (c) catching, and in the case of small prey; (d) carrying (Fox 1971). Several characteristics of the John Stenglein attack suggest the wolf developed a highly aroused predation response because (1) the wolf ventured from the forest to pursue the boy across an open gravel pad; (2) the wolf attempted to carry and drag the boy back to dense cover; (3) the wolf sustained the attack in the presence of rescuers; (4) the wolf reluctantly left the attack site after the boy had been rescued; and (5) the wolf remained hidden in the forest near the attack site and responded to a predator call within minutes after the incident.

When faced with conflicting stimuli, animals can exhibit behaviors that are compounds of separate acts that may be partially inhibited, ambivalent, or alternating (Colgan 1989). The sequence and timing of events in the Icy Bay attack suggest the wolf hesitated before chasing the boy, possibly undergoing a transition from an agonistic threat to a predatory response. The hesitation could also reflect the lack of a prey image for humans, but wolves have been known to change their behavior toward people from submissive to dominant or from habituated to predaceous, based on only one or a few instances where they observe vulnerability (Strickland 1999; McNay 2002a). John ran approximately $40 \mathrm{~m}$ before the wolf attacked. The boy ran slowly and awkwardly in oversized boots, eventually falling. That visual image of vulnerability, accompanied by the boy's cries for help, was probably significant in eliciting the wolf's subsequent response, which was no longer inhibited. The wolf's attempt to carry and drag the boy away from rescuers cannot be explained as an agonistic act and despite the possible agonism reflected in the wolf's initial approach, the final result clearly contained elements of predation.

In a study of wolves $150 \mathrm{~km}$ west of Icy Cape, wolf pack territories ranged from 193 to $597 \mathrm{~km}^{2}$ and averaged $428 \mathrm{~km}^{2}$ (J. Carnes, University of Idaho, personal communication), but only a $100 \mathrm{~km}^{2}$ of useable habitat was available near Icy Bay. The sighting of a female wolf with pups on the road $6 \mathrm{~km}$ from the logging camp suggests the attacking wolf was paired with a female that produced pups, it would be unlikely another adult male simultaneously occupied such a restricted territory.

Typically male wolves carry food to the denning female (Harrington and Mech 1982; Mech et al. 1999). That provisioning places increased energetic demands on the male which could affect predation rates and motivation. For example, predation rates by Coyotes (Canis latrans) on domestic sheep declined when pups of depredating adults were destroyed (Till and Knowlton 1983). Carbyn (1989) suggested nutritional stress on Coyotes during the reproductive season, in combination with habituation to humans, contributed to predatory attacks by Coyotes on children. Coyotes in those attacks behaved similar to the Icy Bay wolf by repeatedly biting the victims, attempting to drag victims away from the attack site, and exhibiting reluctance to abandon their attack even when rescuers intervened.

Some biologists who commented on the attack during the course of the ADPS investigation discounted the idea of a predatory motivation because the wolf was capable of quickly killing the boy, but did not 
(Alaska Department of Public Safety 2000*). However, interruption of the predation sequence can result in confusion, conflicted response, and failure to kill the prey (Zimen 1978). Furthermore, immediate killing is not a prerequisite for successful predation. In Bihar, India, 92 children were preyed upon by wolves between 1989 and 1995. Wolves grabbed children by the neck, waist, head, chest or thigh then carried them away from the attack site. Twenty children were rescued alive after bystanders chased the wolves (Rajpurohit 1999); a 4-year-old boy was rescued after villagers pursued the wolf for $2 \mathrm{~km}$ (Jhala and Sharma 1997). Even with natural prey, wolves commonly do not immediately kill. During Caribou (Rangifer tarandus) calf mortality studies in Alaska, biologists observed wolves carry live calves to cache or feeding sites before killing the calf (R. Boertje, ADF\&G, personal communication). Therefore, predatory intent cannot be ruled out in the Icy Bay case simply because the boy was not killed.

What seems most clear is that the Icy Bay wolf became habituated to the presence of people. Habituation was a factor common to predatory attacks by Coyotes on children in North America (Carbyn 1989) and presumably to wolf predation on children in India where wolves continually live among high densities of people and natural foods are often scarce (Jhala and Sharma 1997; Rajpurohit 1999). In the Icy Bay case, food conditioning may have initially facilitated the habituation process, but there was no evidence the attack resulted from a recently reinforced, food-conditioned approach response.

\section{Acknowledgments}

We are indebted to the people of Icy Bay who openly discussed their experiences related to the attack. Those residents included Betsy Beeks, Samantha Norberg, Carol Simpson, Diane Stenglein, and Teresa Thompson. John Carnes provided unpublished data on wolf home range sizes. We discussed the attack with Trooper Marc Cloward who provided additional insight into findings not presented in his investigative report. We thank Shelley Szepanksi, Beth Lenart, and Laura McCarthy of ADF\&G for preparation of figures and technical editing. Steve Peterson and Patrick Valkenburg of ADF\&G commented on an early draft of this paper.

\section{Documents Cited (marked * in text)}

Alaska Department of Public Safety. 2000. Alaska Investigative Report Case \# 00-29108. Juneau, Alaska.

Blake, J. E. 2000. Veterinary service-diagnostic pathology N00-039. Institute of Arctic Biology, University of Alaska, Fairbanks, Alaska.

\section{Literature Cited}

Carbyn, L. N. 1989. Coyote attacks on children in Western North America. Wildlife Society Bulletin 17: 444-446.

Colgan, P. 1989. Animal motivation. Chapman and Hall. New York.

Fox, M. W. 1971. Behavior of wolves, dogs and related canids. Harper and Row, New York.

Fuller, T. K., L. D. Mech, and J. F. Cochrane. 2003. Wolf population dynamics. Pages 161-191 in Wolves behavior, ecology, and conservation. Edited by L. D. Mech and L. Boitani. The University of Chicago Press, Chicago, Illinois.

Harrington, F. H., and L. D. Mech. 1982. Patterns of homesite attendance in two Minnesota wolf packs. Pages 81-105 in Wolves of the world: perspectives of behavior, ecology and conservation. Edited by F. H. Harrington and P. C. Paquet. Noyes Publications, Park Ridge, New Jersey.

Jenness, S. E. 1985. Arctic wolf attacks scientist - a unique Canadian incident. Arctic 38: 129-132.

Jhala, Y. V., and D. K. Sharma. 1997. Child-lifting by wolves in Eastern Uttar Pradesh, India. Journal of Wildlife Research 2: 94-101

Kimmel, H. D. 1973. Habituation, habituability, and conditioning. Pages 219-238 in Habituation. Edited by H. V. S. Peeke and M. J. Herz. Academic Press, New York.

McNay, M. E. 2002a. Wolf-human interactions in Alaska and Canada: a review of the case history. Wildlife Society Bulletin 30: 831-843.

McNay, M. E. 2002b. A case history of wolf-human encounters in Alaska and Canada. Alaska Department of Fish and Game. Technical Bulletin 13. 45 pages.

Mech, L. D. 1970. The wolf: the ecology and behavior of an endangered species. Natural History Press, New York.

Mech, L. D. 1998. "Who's afraid of the big bad wolf?" revisited. International Wolf 8(1): 8-11.

Mech, L. D., P. C. Wolf, and J. M. Packard. 1999. Regurgitative food transfer among wild wolves. Canadian Journal of Zoology 77: 1192-1195.

Munthe, K., and J. H. Hutchison. 1978. A wolf-human encounter on Ellesmere Island, Canada. Journal of Mammalogy 59: 876-878.

Rajpurohit, K. S. 1999. Child lifting: wolves in Hazaribagh, India. Ambio 28: 162-166.

Scott, P. A., C. V. Bentley, and J. Warren. 1985. Aggressive behavior by wolves toward humans. Journal of Mammalogy 66: 807-809.

Strickland, D. 1999. Algonquin struggles with 'fearless' wolves. Wolf! Magazine 17(1): 7-9.

Till, J. A., and F. F. Knowlton. 1983. Efficacy of denning in alleviating Coyote depredations upon domestic sheep. Journal of Wildlife Management 47: 1018-1025.

Zimen, E. 1978. The wolf, a species in danger. Delacorte Press, New York, USA.

Zimen, E. 1982. A wolf pack sociogram. Pages 282-322 in Wolves of the world: perspectives of behavior, ecology and conservation. Edited by F. H. Harrington and P. C. Paquet. Noyes Publications, Park Ridge, New Jersey.

Received 4 September 2001

Accepted 14 April 2005 